\title{
A CRITIQUE OF THE MORALISTIC CONCEPTION OF CRIMINAL LAW *
}

\author{
By Thomas A. Cowan $\dot{\dagger}$
}

\section{INTRODUCTION}

With the publication of Jerome Hall's General Principles of Criminal Law, legal learning is enriched by the addition, rare nowadays, of a scholarly, patient and currently informed treatise on the important subject of penal liability. To those who know his past work, it will occasion no surprise that the views expressed in the Principles are supported by such considered references to the origins and the historical development of our criminal law as to make serious indeed the task of anyone bent on challenging them. However, it is not with historical origins of the criminal law, but with present outcomes and future perspectives, that we are concerned.

The conviction grew with the reading of the book that Professor Hall's erudition had, in certain very important respects, been devoted to rehabilitating doctrines which were thought outmoded. And since these doctrines, and indeed the whole cast and portent of the book, were the outcome of a general philosophical position taken by Professor Hall, it is felt that only the force of an alternative philosophical position could cope with the views adumbrated in the Principles.

To state these philosophical issues briefly: Professor Hall opposes those whose idea of the nature and purpose of penal liability rests on the philosophical systems known variously as positivism, relativism, or operationalism. He proposes instead that penal liability be founded on what he calls moral consciousness of guilt; that the mens rea be regarded as evil or conscienceless behavior; that violations of legal prescriptions rest on the notion of immoral conduct; and that the aim of criminology be punishment for wrong-doing. This seems to be a return to a vague, subjective moral intuitionism, and it is suggested that the correct alternative philosophy to the positivism which Professor Hall so strongly deprecates is an expanded pragmatic phil-

* The substance of this article was originally delivered at the Round Table on Crimes at the meeting of the Association of American Law Schools, Dec. 27, 1948, the subject of the discussion being Professor Hall's book on criminal law. The reader is asked to note that this paper is a philosophical critique of certain fundamental principles of Professor Hall's work and is in no sense an appraisal of the book as a whole. In point of fact the writer is anxious to state that he heartily endorses Professor Hall's stand with respect to certain major aspects of his analysis of the criminal law, but these aspects are not within the scope of this article.

$\dagger$ B. S., 1926, LL. B., 1931, Ph. D., 1932, Univ. of Penna.; S. J. D., 1933, Harvard; Professor of Law, Wayne University. 
osophical system called "experimentalism." This system in turn demands a synthesis of science and morality that will lead to a newer and broader empirical and objective theory of criminal law rather than the present intuitive and mystical approach to the nature of the criminal mind and penal liability.

Still in summary fashion, but with rather greater particularity, the following are the general notions which form part of the foundation of the General Principles and to which attention will be directed in this paper:

1. The notion that mens rea should refer only to evil intention and that any effort to import motive into criminal law must be resisted. In this view motive may properly be considered only after criminality is determined and thus belongs to the sphere of criminal administration.

2. The notion that criminal mind is an inference from criminal behavior and that the law now possesses techniques that render the probability of making correct inferences in given cases quite high.

3. The notion that the "right-wrong" test for insanity, based on current conceptions of morality, is, when implemented with modern learning, an adequate test for the criminal law.

4. The notion that the over-all aim and objective of the criminal law is and ought to be punishment for wrong-doing, not the correction of socially damaging error.

5. The idea that the techniques and aims of criminal administration (wherein most of the advances in methods of handling criminals are made) should be kept doctrinally distinct from the criminal law.

The above notions had seemed destined ultimately to pass into the history of the criminal law, to be replaced by substitute notions at once more modern and more enlightened. What these more enlightened notions are can be stated in equally summary fashion:

1. The notion that the higher morality of motive might well flood into the criminal law and clean out this Augean stable. Criminal administration should invade the criminal law as equity invaded the common law courts in the eighteenth century.

2. Criminal mind is not an inference from criminal conduct but is a part of criminal conduct itself. In this view mind is an observable object, and, therefore, theoretically at least criminal mind is observable. As a practical matter, however, the science of subjective consciousness remains to be created and it is sheer fantasy to assume that the criminal law is now possessed of techniques adequate to "infer" criminal mind with a high degree of probability. 
3. The notion that the "right-wrong" test for criminal insanity should yield to more refined techniques in the light of the advances of psychiatry and psycho-analysis.

4. The notion that from a moral standpoint the objective of the criminal law ought to be correction, and that punishment degrades not only the victim but also the system which metes it out.

5. The notion that the techniques of criminal administration ought to expand at the expense of the traditional body of the criminal law, as has been the case in the treatment of delinquent juveniles, and that such notions of treatment might with the growth of enlightenment in time absorb the whole content of the criminal law.

In sum, it was hoped that General Principles of Criminal Law might directly lead the criminal law to the threshold of experimental science, rather than, as it appears, backward to eighteenth century moral intuitionism and to a corresponding separation of science from morality.

\section{Mens ReA}

Hall objects to two very important current tendencies to change the classic conception of mens rea. These are first, a tendency to "confuse" motive with intention. The second is more serious: a tendency to abolish altogether the element of mens rea from penal law, the so-called Holmesian doctrine of objective liability.

First, about the confusion of motive and intention: Hall calls attention to the classical learning on the subject. He says, ". . . hardly any rule of penal law is more definitely settled than that motive is irrelevant." 1 Certainly Austin, Stephen and Sayre, who are said to be guilty of the confusion, knew this rule. Everyone knows it. So doubtless Austin, Stephen and Sayre had strong "motives" for attempting to change the rule; and equally without doubt Hall has strong "motives" for arguing for its retention.

The most celebrated proponent of the theory that motive alone is concerned with moral culpability is Stephen; following him is Sayre. The effect of this doctrine is to exclude from the concept of the mens rea any reference to the "intentionality" of the criminal act. Austin's "confusion" was the opposite. Motive is reduced to a species of intent and the moral significance of motivated action is ignored. Just in passing, it is rather surprising to hear from Professor Hall that Austin, of all people, had "confused" motive with intent. On the contrary, his identification of the two is quite in accord with his general "amoral" system of analytical jurisprudence.

1. Hall, General Principles of Crmminal Law 153 (1947). All subsequent references to this volume will be by page number only. 
To "confuse" motive with intent is, of course, indefensible. The distinction is a commonplace one. But the question remains : what led Stephen and Austin to their "incorrect" views of the nature of mens rea? And what of the pressing question of motive in the criminal law? We can pass by as sufficiently discussed in current jurisprudential literature Austin's "amoral" analytical jurisprudence. ${ }^{2}$ But Stephen, and after him Sayre, and indeed many present day teachers of criminal law are of the opinion that motive must find its way into the criminal law "in some way or other." That motive is related to higher ethical ideals than intentionality is apparent. From a purely pragmatic point of view, is it not reasonable to suppose that criminal law will ultimately benefit from the "confusion" of motive with intent?

In other words, what price clarity of concepts in this trouble-land of the criminal law? For certainly, Professor Hall who ultimately bases the sanction of the criminal law on morality must admit that the ends of that law will be "fed from above" by importing somehow or other the higher standards of a "motivation" ethics. If motive and intention are to remain "unconfused," but if the higher ethics of motive is to be effective in the legal disposition of crime, then Professor Hall has made the hard choice of confining intentionality to the substantive criminal law and motive to criminal administration. But surely this is to purchase clarity of analysis at too high a price. Professor Hall has much to say in approval of the important part which motivation plays in the administration of modern penal law. Unfortunately, for him its beneficent and enlightened effects come into play only after the criminal law has made its fateful disposition, whether of conviction or acquittal. In cases of acquittal, the modern machinery of administration does not, in the main, have even an opportunity to move. In cases of conviction, it can only attempt to undo an evil already inflicted.

The unfortunate consequences of this strengthening of the methodological distinction between criminal law and criminal administration appear dangerous. For, if, as Professor Hall has emphasized, it is immoral to break a penal law-a doubtful proposition at best without the qualification ethical writers usually give it-it is also highly immoral to disregard motive in the "determination" of criminality. Subsequent efforts to mitigate the evil by wise administration come, in the main, too late. This is the lesson to be gathered from those who administer the law respecting juvenile delinquency. Inasmuch as Professor Hall feels that analysis forces motive out of the "law" and into "administration" the present writer feels equally impelled to 
reject that analysis despite 'Professor Hall's conclusion that "such absolute evaluation in substantive penal law may be defended on the ground that the nature and functioning of that law require a degree of fiat." 3 Perhaps fiat is necessary; perhaps not. But it is hard to see why the criminal law requires that particular fiat, instead of another framed in a more progressive way. Must criminal law always remain the most hide-bound and unprogressive branch of the law, while criminal administration is, in some respects at least, the most lawless? Would not criminal administration become more orderly if criminal law were less rigid?

\section{ObJective Ltability}

We turn now to more difficult things-specifically, to Holmes' theory of objective liability. This theory may be summed up in the words of the great jurist as quoted by Professor Hall, "while the terminology of morals is still retained, the law . . . by the very necessity of its nature, is continually transmuting those moral standards into external and objective ones, from which the actual guilt of the party concerned is wholly eliminated." 4

Holmes' idea of how the guilt of the party is or should be eliminated from the law takes two forms. One is a callous disregard of individual moral differences since in enforcing the criminal law the state is taken to be interested only in expediency and in group preservation. There can be little quarrel with Professor Hall's condemnation of this aspect of Holmes' objective theory. Hall says, "As Holmes proceeds to implement 'expediency' he sometimes displays a surprising, and, occasionally, an even shocking insensitivity." 5

Holmes' other meaning of objective liability is more important. "The tests of liability are external, and independent of the degree of evil in the particular person's motive or intentions." 6

The epistemological foundation of this doctrine (nowhere made explicit by Holmes) is of course positivism, the philosophical doctrine which looks to external behavior rather than to mental states; which prefers to concentrate on observable data rather than ultimate causes; and which in its extreme form reduces human motivation to crude external preference-seeking. Positivism as a philosophical system was designed in the last century to help substantiate the claims and biases of a rapidly growing natural science and of the embryonic but hopefully regarded social disciplines.

3. P. 159.

4. P. 170 .

5. P. 172 .

6. P. 173 . 
Any attack on positivism, legal or otherwise, is bound to have its effect on scientific theory. Customarily, the attacks on positivism have taken two forms. One is a principled rejection of positivism's latent tendency to subject all matters of investigation to the test of experimental science on the ground that certain phenomena are of such a character that they are not amenable to scientific method. The other accepts in principle the scientific and empirical tendencies of the positivistic epistemology but attacks it as crude, narrow, and vulnerable to anti-scientific forays on the part of those who wish to keep science and ethics separate, and who argue for the "sanctity" and "inviolability" of subjective consciousness.

The better position towards positivism, pragmatism and operationalism would seem to be the second of these alternatives. Briefly put, it seems a mistake to surrender "morality" and "subjective consciousness" to anti-scientific forces. The remedy is to expand experimental method to take in these hitherto non-scientific areas of human activity.

Now, despite a close reading of Professor Hall's chapter on Objective Liability and related sections, I am unable to state with any degree of confidence what is Professor Hall's position on the above issue. It would seem that for Professor Hall mens rea must be objectively determined, for he bases it on an objective ethics. But nowhere do I find a positive statement to the effect that mens rea is not a subjective phenomenon. It therefore seems to be his view that the criminal state of mind is subjectively experienced in the criminal, but that its determination is objective for the criminal law, in some sense more refined than that of Holmes. This leads directly to a splitting of criminal mind into two parts : subjective and objective. The subjective aspect of criminal mind is to be inferred solely from objective conduct, but is not itself objective conduct. The following statement of Holdsworth for example is quoted by Hall with approval:

We must adopt an external standard in adjudicating upon the weight of the evidence adduced to prove or disprove mens rea. That, of course, does not mean that the law bases criminal liability upon non-compliance with an external standard. So to argue is to confuse the evidence for a proposition with the proposition proved by that evidence.

This reintroduces and highlights the difficulty with non-pragmatic or non-positivistic notions of the nature of mens rea and it leads to unscientific intuitions about the nature of criminal mind that are often astonishing. For example, noting that Holmes recognized the 
"peculiar inaccessibility of inner states of mind to direct observation," Professor Hall ventures a statement of fact which is not only wholly uncorroborated, but in the present state of experimental psychology cannot be corroborated, and which therefore could be just as vehemently denied as asserted. It is this:

For while it is literally true that we can never certainly say more than that under given conditions a rational being, $i$. e., a "reasonable man," would or would not have "intended" etc., yet, for the reasons noted above and because modern legal procedure comprises skillful methods of discovering external facts, the probabilities are high not only that the external facts have been accurately determined but also that the inference drawn from them regarding "intentional conduct" fits the particular defendant on trial. ${ }^{8}$

This is really a most remarkable statement from one deeply learned in the vagaries of the criminal law. Setting aside the question of whether modern legal methods are skillful to determine external facts, it is the sheerest lighthearted optimism to assume that inferences from them fit the "intentional conduct" of the particular defendant on trial. For no known techniques exist "adequate" or "skillful" enough to determine subjective consciousness. It is in the intuitive conviction contrary in character to Professor Hall's where one can look for the development of techniques adequate to this investigation. If Professor Hall were to say that bad as they are, the present techniques are all we have and subjective consciousness must as yet go largely undetermined, the moral import of the comment would be healthier.

The same spirit of misleading optimism is repeated in this passage :

The whole law of evidence is a studied effort to cope with this fundamental problem and its chief raison d'etre rests on the high probability of a "sufficiently" accurate representation of inner states by external conduct and the consequent validity of the relevant findings of fact. ${ }^{9}$

Probability is, or should be, a scientific term and anyone who applies it to the law of evidence must intend it to be understood with all the limitations of that body of law. It may mean that the probability of accurate representations of inner states by external conduct is high enough to suit the average practitioner or the average judge or the average person well-content with the law of evidence as it now stands. If the phrase means this, then it seems to misrepresent the average of informed opinion about the law of evidence. In any event,

8. P. 179.

9. P. 180 . 
in the total absence of scientific devices or indeed even crude empirical techniques for determining subjective consciousness, one man's opinion is as good as another's, and I for one prefer to believe that the "probability" of reaching a criminal's true subjective intent mentioned in the two extracts above is not "high" but very low indeed.

This leads directly to a criticism of the view that in and of themselves mental states are inaccessible, but that external conduct may be evidence of them. One asks at the outset how, if mental states are really inaccessible, one knows what the external conduct offered as evidence is evidence of? If you offer evidence of the existence of a pig in a poke by drawing attention to squeaks and grunts emanating from the poke, by the shape of the outline, and in other ways, I should hope that sooner or later this evidence may be either confirmed or refuted. But if I were told that neither you nor any other man had ever seen a pig in a poke, that by the nature of the situation the pig was "inaccessible" then I should have to say either that your pig did not exist, or else its existence was of a different character from ordinary material existence as I knew it.

Once admit, as Holmes and many others do, that another's mind is really and essentially inaccessible then no evidence can ever be offered to determine its nature, for the evidence by definition is not subject to either confirmation or rejection. The way out of the dilemma is the one modern psychology is coming more and more to accept.

Mind is a way of acting. External behavior is not evidence of mind. If the behavior is of a certain specified character, it is mind. The concept of mind is being defined operationally. Just as it was common half a century ago to say of electricity "we do not know what it is, but we know what it does," just so our jurists say even today, "We do not know the subjective state of mind of another, but we know its effects in external behavior." Modern operationalism on the contrary, demands that both concepts be defined in ways that can make understanding them within the reach of science. Consequently it says in effect, "Electricity is what it does." Can we not also say, "Subjective consciousness is what it does"?

This view leaves open the road to experimental progress, just as the view of essentially inaccessible states of mind closes it. It may be naive to hope that experimental social science will take up the task, but at times even "utopian" schemes for progress are better than the complacency of mature, common-sense, conservative opinion.

Once again, it is difficult to say whether Professor Hall subscribes to essential inaccessibility of states of mind. If he does, the above 
criticism of Holmes' position applies as well to him. Certainly there is no hint in the treatise that Professor Hall intends to espouse an operational definition of mens rea. All the observed references are couched in terms of inferences from external behavior to internal states of mind. Traditionally the theory which infers mind from behavior has always rested ultimately on the view that states of mind themselves are inaccessible to direct observation. And inaccessible states of mind are mystical entities forever beyond the reach of science.

In a previous paper, ${ }^{10}$ the author proposed that the thesis that mind is an observable object be applied to the concept of the mens rea. The result to be expected from such a doctrine is that mind is not something to be inferred from behavior; it is behavior, behavior of a very particular kind, to be sure, but behavior nonetheless. This proposal would entail the abandonment as idle, of any attempt to treat subjective states of mind as anything other than observable behavior. This would supply for experimental psychology an epistemology congenial to its needs; one that, indeed, without conscious formulation, it has long been using anyway. To the extent that subjective states of mind are not susceptible of observation they remain for the criminal law unsolved problems.

This doctrine need not deny that the subject matter of the criminal law includes the moral aspects of criminality. It does demand, however, that these moral aspects of criminality be open to precisely the same kind of investigation as the other aspects of criminality. In sum, it would insist upon an experimental ethics. And it is precisely at this point that Professor Hall, in spite of his repeated assertion that in his view ethics is objective, will probably part company with the writer. If he does not, so much the better and his objective ethics may be conjoined with objective legality to form, it is hoped, an experimental foundation for criminal law. How such experimentation should proceed must remain open at this point. Suffice it to say, that the advance may be made through an extension of criminology, a virtual invasion by criminology of the field of criminal law, and this proposal runs directly contrary to the whole import of Professor Hall's book.

\section{The Right-Wrong Test for Criminal Insanity}

Although it had first seemed possible to avoid crossing swords with Professor Hall on the question of the dark jungle-land of the criminal law-the problem of criminal insanity-it became quite evident

10. Cowan, Toward an Experimental Definition of Criminal Mind, PHILosopHrCaL Essays in HoNor of EDGaR ArthuR Singer, JR. 163 et seq. (Clarke \& Nahm ed. 1942). 
from his chapter on Mental Disease that one's views on mens rea are very apt to be of a piece with views on mental disease. Professor Hall's remark that "the criticism of the 'right and wrong' test by the . . . psychiatrist-critics represents a phase of modern Positivism," 11 makes it clear that we are dealing with a philosophical issue. As such, the argument cannot be avoided by one who believes that positivism is in the "right line of descent" to a philosophy of experimentalism.

As the basis for the development of this latter view, then, let us refer to the eminently "sane" views of Professor William E. Mikell, beloved professor of criminal law for a long generation at the University of Pennsylvania Law School. Drawing attention to the fact that the "right-wrong" test taken alone was pre-eminently an intellectualistic one since it referred exclusively to the ability of the defendant to ratiocinate normally, while the "irresistible impulse" taken alone referred solely to the normality of the defendant's emotional life, Professor Mikell came to the conclusion that if such a test be insisted upon then both aspects of the mental apparatus would have to receive adequate attention. Neither irrationality nor psychotic emotional instability could be relied on as "the principal criterion of insanity." To select either as the principal criterion would reveal a one-sided preference for certain aspects of the mental life to the neglect of others. But going further, Professor Mikell questioned the propriety of relying on any legal tests whatever in the determination of criminal insanity. Insanity, he taught, is a question of fact, just as mens rea or its absence is a question of fact; just as the question of tuberculosis vel non for a health and accident or war risk insurance policy is a question of fact. The legal conclusion is, "Was the accused insane?" This conclusion must be arrived at as is any other disputed, complex question of fact: Certainly, subordinate rules of law often facilitate the determination of questions of fact where the state of common learning or scientific knowledge or policy of the law permit such shortcuts to the resolution of disputed matter of proof. But in the state of present lay and professional opinion on the subject of insanity, the wise, though not the accepted rule, and the one least likely to foreclose access to scientific knowledge by both judge and jury, is the rule that the law knows no test at present which it prefers in the determination of criminal insanity.

Professor Hall advocates the retention of the M'Naghten Rules, amended to include "reference to the emotional and volitional aspects of conduct." 12 But-and herein lies his preference-"such amended 
Rules would continue the present emphasis on irrationality as the principal criterion of insanity, but the formulation suggested above, implemented by an informed administration of the law, would provide a new interpretation of that criterion, which would probably be approved by most psychiatrists." 13 Nothing but a careful reading of the entire chapter, in the light of the whole thesis of the book, would suffice for a thorough appreciation of the considerations which support Professor Hall's view. Modern advances in psychiatric knowledge are taken account of, and the evident intention is that the Rules should be interpreted in the light of such informed counsel. Still, when all this is said, the preference remains substantially unaffected. "As a practical matter, at least for the immediate future, it seems preferable to proceed as indicated above, $i$. e., by amending the present Rules." 14

Although volitional psychology is still in its infancy, the infant is a vigorous child indeed. No reference is here intended to psychoanalytic psychologists whose concern is not sensation, nor perception, i. e., knowledge in the sense of the M'Naghten Rules, but rather volition or will. Professor Hall himself says, "Viewed historically, there can be little doubt that the M'Naghten Rules represented an intellectualistic psychology." 15 Viewed prospectively even with Professor Hall's amendments, there is equally little doubt that the emphasis is still on an intellectualistic psychology, since irrationality is still to be the principal criterion of insanity. At this point we should ask whether students of the law are in a position to state that the principal criterion of criminal insanity should be intellectualistic. It might even emerge from a scientific study of personality that preferences for "intellectualistic" or "emotionalistic" interpretations are themselves temperamental. At any rate, and in the absence of a science of personality, such preference itself looks "irrational," however many judges and students of the law "prefer" it.

That the "intellectualistic" preference is not unrelated to Professor Hall's general thesis was to be expected. We have just seen that it appears to him that the moral foundation of criminal responsibility rests on the basis of a "right-wrong" test for liability when the defense is insanity. It will be recalled that in distinguishing intent from motive, Professor Hall had offered as an example the commonly understood difference between right-wrong and good-bad aspects of human conduct. ${ }^{16}$ Intent in law rests on the "right-wrong" dichotomy; motive on "good-bad." The volitional psychology deals

13. P. 536.

14. P. 537.

15. P. 505.

16. P. 141. 
with motives, the stimulus of the will to action. Hence, Professor Hall's subordination of the volitional to the rational aspects of conduct is "integrated." Moreover, as might be expected, it leads to certain similar moral conclusions on the end and aim of the criminal law, i. e., the theory of treatment versus punishment.

Stung by the repeated ungenerous and largely uninformed attitude of psychiatrists, and particularly those modern masters of invective, the psychoanalysts, toward the problems of criminal law and its administration, Professor Hall pays them off in their own coin by showing the wild state of disorder and confusion which characterizes their "science." The rancor of the age-old dispute between the "learned professions" may well account for the emotional overtones with which Professor Hall attacks the flowing insolence of these modern successors of the medieval witch-doctors. The sound drubbing administered is to be applauded, but as to emotional overtones only. There is a steady progression of evidence in the chapter to establish or at least to buttress the theory that the end of the criminal law is punishment not treatment. Herein, the aid of "sound" psychiatrists and psychoanalysts is accepted by Hall for what support it may lend to the "punishment" thesis.

The question of the ultimate aim of the criminal law, as of the ultimate aim of law in general, is a moral one. Moreover, it is a matter on which every citizen is entitled, and indeed by his conscience commanded, to form an opinion. If one feels that the problem of crime should be solved in the same way that deviations from a norm of physical health are solved, he also feels it incumbent on the experts in the field to bring about that happy consummation as rapidly as possible. The issue, then, is not one between a moral as opposed to an amoral or immoral view of the function of criminal law. Thus, despite the fact that certain positivistic psychiatrists call on the criminal law to disregard "all moral issues," 17 nevertheless, when their "positive" program is examined, it is seen to rest on a moral and humanitarian basis of a character actually far higher than Professor Hall's moral foundation for punishment.

If the issue is that these radical practitioners are ignorant of the peculiar problems of criminal law and administration, or that they confuse "justice," "deterrence," and "rehabilitation," or that they make "the untenable assumption that adequate empirical knowledge is available to rehabilitate or even to recognize with assurance those who can and those who cannot be reformed," 18 then we may be forced, 
with reluctance, to agree with Professor Hall. But if it means that these present limitations of psychiatry and criminal administration set the goal of the law at what is to be regarded as the base ideal of punishment rather than the lofty one of treatment, then we should most emphatically disagree.

To take an example out of the past: The human race has again and again committed itself to the theory that punishment for physical illness is morally justifiable. The sick, it has often been thought, are evidently being punished by divine intervention for some "crime" unknown to men, but undisputably evidenced by the visitation of the wrath of the gods. Insanity has often been so regarded. It would be idle to resist the intrusion of psychiatric medicine into the criminal law, either because the psychiatrist's state of empirical knowledge is woefully weak, or because the exigencies of a theory of the moral nature of punishment render peculiarly inept the "interference" of those who by temperament and training are qualified only "to cure" and not "to punish."

\section{Criminal Law and Criminology}

In his concluding chapter, Professor Hall examines at length the interrelation between his view of the nature of criminal law and what he takes to be the purpose and aim of criminology. The result is a masterful critique of the loose, slip-shod, and, as it often appears, dangerously uninformed views of the "positivistic" criminologists or of those working on the borders of criminology and some branch of biological or social science.

This is the kind of deserved attack all "naive" positivists or relativists may well expect to provoke. Reference has already been made to the examination of this issue from a general epistemological point of view by the writer. ${ }^{19}$ There the empirically-minded positivists and relativists or operationalists were warned that unless they were prepared to surrender to "non-experimentalist" investigators some of the most important realms of modern inquiry, such as the nature of morality, subjective consciousness, personality, "free will," and the like, they would have to expand enormously their conception of experimental method and set about to devise ways and means of bringing these matters within the sphere of experimental science.

Professor Hall provided in this chapter one of the most telling criticisms of the narrow positivistic perspective, which, since it fails to provide an adequate base for experimental work and yet refuses to

19. See note 10 supra. 
abdicate these problems to non-scientific investigation, is forced to deal with them on an emotional and intuitive basis that often outrages common sense. The off-hand way with which positivism substitutes "treatment" for "punishment" as the end and aim of the penal law, the easy generalization that all criminals are "sick," the sentimental abhorrence of the use of force by civilized society, these and like sentiments come in for rather severe handling by the learned writer of the treatise. The following extract (one among many) forcefully illustrates the point:

The conflict between the criminologist's professed scientific predilections and his common sense is nonetheless plain. As "scientist" the contemporary criminologist is not concerned with ethics; as an ardent proponent of positivistic sociology, he embraces determinism. $\mathrm{He}$ is interested only in mores, not ethics, and since they vary temporospatially, the criminologist is a relativist; but, in the spirit of Carpenter, Darrow and Ross, he becomes a vehement evangelist when he appraises the misconduct of the rich and powerful even when they have admittedly violated neither mores nor penal law. In his complete repudiation of "punishment," he pretends to rely on verifiable data; but in his espousal of rehabilitation and "protection to society," he exhibits a strange combination of "humanitarianism" and calculated cruelty. In fear of ancient superstitions, impenetrable mysticisms and dogmatic theologies, far too many contemporary criminologists have taken refuge in equally indefensible dogmas. Dogma, however, cannot be refuted by counter-dogma. Anyone who advances the thesis that a thorough consideration of moral values must be included in any sound criminology must nonetheless recognize that the prevailing bias against this position is far from groundless. The recourse of the critic of contemporary criminology, as well as that of any other social theorist can only be defense of the least vulnerable position. ${ }^{20}$

There follows a most enlightened plea that the criminologist in his work realize that he is dealing not with a mechanism, an automaton. On the contrary, his data involves consideration of a moralizing, problem-solving, value-experiencing human being in a social setting of a character so complex as to render ineffective, and therefore dangerous, the narrow dogmas of positivism. So far so good. But what is the outcome of this impassioned plea for the larger view, the moral character of the criminal law, and criminology's failure to take account of it? Unfortunately, it is just what might be supposed from a writer whose attacks on positivism are not directed to its incomplete character, but rather to its alleged weak-kneed morality. The moral

20. Pp. 565-566. 
foundation of the criminal law is taken by Professor Hall to be force, and the object of the criminal law is taken to be punishment. In other words, Professor Hall, in rejecting the looseness of modern positivism, returns to the tightness and stringency of positivism's remoter ancestors. And the strange spectacle emerges that whereas the modern positivists (late sons of Hobbes) are characterized by a loose humanitarianism, their critic returns to the stricter moral doctrines of the master of the theory of law as force, Hobbes himself. For example:

Accordingly, it may be concluded that those supreme norms which symbolize social interests and apply to the entire community, whose sanction is force that operates rather specifically as prescribed and in total disregard of the offender's volition, can be distinguished from other norms and may properly be designated "rules of law." 21

There is nothing in this definition of the criminal law that Hobbes would not approve of. It chooses to single out force as the mark of the law. Moreover this notion of force is that it is moral force. To disobey the criminal law is immoral. Thus force, that of the state to be sure, and only in the case of violation of its proscriptions, is raised to the order of the moral. Paraphrasing Holmes we might ask whether it is not rather that recourse to force is merely a necessity. It can hardly be dignified by the term "moral duty."

And, on practical grounds, in this day of the modern police state, the insistence of theorists upon the moral duty of the state to exercise force in punishing the violators of its laws is surely a work of supererogation. Perhaps current positivists are remiss in this respect, but totalitarian and semi-collectivist modern states are hardly likely to suffer from the oversight.

One recalls the wise remark of Hobbes written when the need for exacting obedience to the monarch's whims was not so compelling as in the times which witnessed the production of Leviathan. "In matters of government, when nothing else is turned up, clubs are trumps."

In Professor Hall's attack on loose positivist views respecting punishment he once again illustrates the danger of a non-experimental critique of positivism. For him the ultimate aim of the penal law is the retrogressive idea of punishment. After noting that philosophy is a necessary adjunct to an adequate criminology and the challenge to the criminologist is to articulate his philosophical position, Professor Hall then articulates the philosophy of punishment for him.

This need is most readily apparent in the thesis that punishment is a useless relic of barbarism, a disguised expression of

21. P. 556. 
man's lust for vengeance, lacking any rational support. The fact is that these claims have not been substantiated. Whether crime has increased or decreased over the centuries and the relationship of punishment thereto are so enormously complicated . . . as to render any alleged determination highly dubious. ${ }^{22}$

Of course, one cannot prove by a reference to history that punishment is barbarous vengeance. The issue here is what ought to be the purpose of the criminal law, not what has been the effect of punishment in the past. Suppose it be freely admitted that the present apparent aims of the state can only be attained by punishment, then so degrading a system of law ought to be changed. Professor Hall here invokes philosophy to sustain a theory of penal liability which many people, including the writer, think is degrading. $\mathrm{He}$ could well have cited important philosophical opinion in support. But other philosophical and ethical opinion, both Greek and Christian, condemns this view as unworthy the dignity of man.

To re-enforce it, Professor Hall makes other statements of equally doubtful ethical value.

Certain elementary matters are hardly disputable, e. g., that the criminal law represents and implements basal social values; that punishment cannot be understood apart from the philosophy thus implied; and that it is therefore fallacious to confuse punishment with cruelty just as it is erroneous to identify "retribution" with revenge. ${ }^{23}$

So disputable are these conclusions, on the contrary, that it would be just as true and certainly more in accord with a sound morality, to assert their direct negatives.

\section{Conclusion}

The conclusion to this critique can be very brief. The criticism was aimed at a "moralistic" conception of the criminal law, the insidious effects of which are, in the writer's opinion, just as unfortunate as those of a crude and narrow positivism. To call the General Principles of Criminal Lawe a "moralistic" treatise would itself be meretricious. But that it tends to debase "morality" to a "moralistic" level and that it lends aid and comfort to those whose interests and discernments are not as lofty as those of Professor Hall seems to be inescapable. Where Professor Hall's strictures are directed to the failures and shortcomings of positivist theories of the nature of crim-

22. Pp. 568-569.

23. P. 569 (emphasis added). 
inal mind, of the general character of the criminal law, and of the end and aim of penal liability, I find myself heartily in accord. But where, in reacting to these positivistic breaches and lacunae, Professor Hall reverts to inner states of consciousness as the basis of a general conception of mens rea, to an intuitively held non-experimental theory of ethics and of the moral nature of criminal proscriptions, to a deepening of the rift between criminal law and criminal administration, and to a reaffirmation of "punishment" rather than scientific and humanitarian "treatment" of criminal offenders, then I find that he lends his authority to present day mystical opponents of a sound empirical and scientific foundation for penal liability. 